(RESEARCH ARTICLE)

\title{
Antioxidant and proton potassium ATPase inhibitory activity in fruits
}

\author{
Nanda B L. \\ Department of Biochemistry, Maharani's science college for women, Mysuru, Karnataka, India.
}

Publication history: Received on 26 May 2019; revised on 20 June 2019; accepted on 27 June 2019

Article DOI: https://doi.org/10.30574/gscbps.2019.7.3.0093

\begin{abstract}
In the present study fruits such as Kiwi, Persimmon, Pomegranate, Dragon and Noni were screened for their antioxidant activity and $\mathrm{H}+\mathrm{K}+$ ATPase inhibitory activity. Among various mechanisms involved in the formation of gastric ulcers, free radicals generated during stress are one of the major causative factors for the gastric lesion through oxidative damage. Thus the best approach to control gastric ulcer would be to inhibit oxidative damage and acid secretion induced by the enzyme. The proton potassium ATPase inhibitory and antioxidant activity of aqueous and acetone extracts of five different fruits were investigated. The fruits were subjected to phytochemical investigations, antioxidant activity and enzyme inhibition. Among the various fruits screened Noni fruit showed $96.5 \%$ enzyme inhibition with considerable amount of phenolics and flavonoids. It showed $80 \%$ of free radical scavenging activity and $50 \%$ of anti-lipid peroxidation activity.
\end{abstract}

Keywords: Pomegranate; Noni; Gastritis; Antioxidant; Proton potassium ATPase inhibition

\section{Introduction}

Gastritis is the inflammation of the lining of the stomach. The stomach normally secretes acid that is essential in the digestive process. This acid helps in breaking down the food during digestion. When there is excess production of acid by the gastric glands of the stomach, it results in the condition known as acidity. Acidity is responsible for symptoms like dyspepsia, heartburn and the formation of gastric ulcers. Gastric ulcers may develop due to stress, bacterial infection and use of the non-steroidal anti-inflammatory drugs [1-3]. Among various causes, stress generated free radicals and infection are the major factors for development of gastric lesions through oxidative damage [4-5].

Proton pump inhibitor (PPI) therapy is thought to primarily protect gastric mucosa by inhibiting gastric acid secretion. The radicals also promote mucosal damage by causing degradation of the epithelial basement membrane components, complete alteration of the cell metabolism and DNA damage [6]. It is known that radical scavengers play a significant role in protecting membranes from oxidative damage.

The primary objective of this work is to explore the biochemical components, antioxidant activities and antiulcer activity in fruits. Fruits and vegetables are rich in secondary metabolites such as phytochemicals. They are antioxidant rich and helps to protect us from free radical mediated diseases like heart disease, cancer, arthritis, stroke, respiratory diseases, immune deficiency, Parkinson 's disease and other inflammatory conditions.

\footnotetext{
${ }^{*}$ Corresponding author

E-mail address: nandasathish2007@gmail.com
} 


\section{Material and methods}

The Kiwi (Actinidia deliciosa), Persimmon (Diospyros kaki), Pomegranate (punica granatum), Dragon (Hylocereus undatus) and Noni (Morinda citrifolia) fruits were obtained from local market. Unless otherwise stated all chemicals used in these experiments were of analytical grade, obtained either from Merck or Sigma chemicals or SRL chemicals.

\subsection{Extraction}

Kiwi, persimmon, pomegranate, dragon and Noni fruits were cleaned and washed with distilled water. $1 \mathrm{~g}$ of four different types of whole fruits were taken and ground with $10 \mathrm{ml}$ of distilled water and $10 \mathrm{ml}$ acetone using pestle and mortar and centrifuged at 10,000x g for 10 minutes at $4{ }^{\circ} \mathrm{C}$ in a cold centrifuge and filtered through Whatmann No.1 filter paper. The aqueous and organic solvent extracts were evaporated to drynesss. The yield was calculated and expressed in percentage. The extracts were dissolved at $1 \mathrm{mg} / \mathrm{ml}$ concentration for performing various activities.

\subsection{Estimation of total sugars}

Total sugars were estimated according to the procedure of phenol-sulphuric acid method [7]. Total sugars were expressed in terms mg of glucose/g of flower. Glucose (0-25 $\mu \mathrm{g}$ ) was used as reference standard.

\subsection{Determination of total phenolics by Folin-Ciocalteau assay}

The concentration of total phenolics in all the extracts was determined by the Folin-Ciocalteu assay. It involves reduction of the reagent by phenolic compounds, with concomitant formation of a blue complex, its intensity at 725 $\mathrm{nm}$ increases linearly with the concentration of phenolics in the reaction medium [8]. In this study Gallic acid was used as spectrophotometric standard. The phenolic contents of the extracts were determined from calibration curve and were expressed in mg of Gallic acid equivalents/g sample.

\subsection{Estimation of total flavonoids}

Aluminium chloride colorimetric method [9] was used for flavonoids determination. The absorbance of the reaction mixture was measured at $420 \mathrm{~nm}$ with UV visible spectrophotometer. The content was determined from extrapolation of calibration curve which was made by preparing Gallic acid solution in distilled water. The concentration of flavonoid was expressed in terms of $\mathrm{mg} / \mathrm{g}$ of sample.

\subsection{Antioxidant activity by DPPH method}

Determination of antioxidant activity by the DPPH method [10] was done for all the extracts. Diphenyl-1-picryl hydrazyl (DPPH) was used as a stable radical for assessing antioxidant activity. Reduction of DPPH by an antioxidant or by a radical species results in a loss of absorption at $517 \mathrm{~nm}$. Thus the degree of discoloration of the solution indicates the scavenging efficiency of the added substances. Percentage of radical scavenging activity was calculated for all the extracts.

\subsection{Determination of reducing power}

Substances, which have reduction potential, react with potassium ferricyanide $\left(\mathrm{Fe}^{3+}\right)$ to form Potassium ferrocyanide $\left(\mathrm{Fe}^{2+}\right)$, which then reacts with ferric chloride to form ferric ferrous complex that has an absorption maximum at 700 $\mathrm{nm}$. The reducing power of all the extracts was evaluated according to the method of Oyaizu [11]. The absorbance was then measured at $700 \mathrm{~nm}$ against blank sample.

\subsection{Antioxidant activity by TBA method}

Thiobarbituric acid (TBA) reacts with malondialdehyde (MDA) to form a diadduct, a pink chromogen, which can be detected spectrophotometrically at $532 \mathrm{~nm}$ as per Halliwell and Gutteridge [12]. The egg yolk was used for the study of invitro lipid per oxidation. The percentage of anti- lipid per oxidative activity (\%ALP) is calculated for all extracts.

\subsection{Determination of proton potassium ATPase inhibition}

\subsubsection{Preparation of $\mathrm{H}^{+} K^{+}$ATPase enzyme}

To prepare $\mathrm{H}^{+}, \mathrm{K}^{+}$-ATPase enzyme sample, fresh sheep stomach was obtained from a local slaughterhouse at Mysore market, Karnataka, India. The stomach was cut opened, the mucosa at gastric fundus was cut-off, and the inner layer was scraped out for parietal cells [13]. Thus obtained cells were homogenized in $16 \mathrm{mM}$ Tris buffer (pH 7.4) 
containing $10 \%$ Triton X-100 and centrifuged at $6000 \mathrm{~g}$ for $10 \mathrm{~min}$. The supernatant (enzyme extract) was used to determine the $\mathrm{H}^{+} \mathrm{K}^{+}$-ATPase inhibition.

\subsubsection{Assesment of proton potassium inhibition}

The reaction mixture containing $0.1 \mathrm{ml}$ of enzyme extract and different fruit extracts at $100 \mu \mathrm{g}$ concentrations was pre incubated for $60 \mathrm{~min}$ at $37^{\circ} \mathrm{C}$. The reaction was initiated by adding substrate $2 \mathrm{mM}$ ATP $(200 \mu \mathrm{L})$, in addition to this 2 $\mathrm{mM} \mathrm{MgCl} 2(200 \mu \mathrm{L})$ and $10 \mathrm{mM} \mathrm{KCl}(200 \mu \mathrm{L})$ was added. After $30 \mathrm{~min}$ of incubation at $37^{\circ} \mathrm{C}$, the reaction was stopped by the addition of assay mixture containing $4.5 \%$ ammonium molybdate and $60 \%$ perchloric acid followed by centrifugation at $2000 \mathrm{~g}$ for $10 \mathrm{~min}$ and inorganic phosphate released was measured spectrophotometrically at 660 $\mathrm{nm}$ by following Fiske-Subbarow method [14]. Briefly, to the $1 \mathrm{ml}$ of supernatant $4 \mathrm{ml}$ of millipore water, $1 \mathrm{ml}$ of $2.5 \%$ ammonium molybdate, $0.4 \mathrm{ml}$ of ANSA was added and allowed to stand for $10 \mathrm{~min}$ at room temperature. Absorbance of released inorganic phosphate was measured at $660 \mathrm{~nm}$. Enzyme activity was calculated as micromoles of $\mathrm{Pi}$ released per hour at dose of $100 \mu \mathrm{g}$ of each extracts.

Percentage of enzyme inhibition was calculated by using the formula:

Percentage of inhibition $=[$ Activity $($ control) - Activity (test) $/$ Activity (control) $] \times 100$.

\section{Results and discussion}

In recent days emphasis has been on the use of edible sources for maintenance of the health. Fruits are considered as one of the antioxidant rich source for combating free radical mediated diseases. Gastric mucosal damage due to the hypersecretion of gastric acid through $\mathrm{H}^{+} / \mathrm{K}^{+}$-ATPase action is used as one of the strategy in the management of hyperacidity by inhibiting proton potassium ATPase. Although several synthetic proton pump inhibitors (PPIs) such as omeprazole, pantoprazole, lansoprazole, rabeprazole, and esomeprazole are available for use to manage hyperacidity in individuals with gastrointestinal disorders, most of these drugs come with several adverse effects[15,16] which are not tolerated by some individual. In the present study inhibitory and antioxidant activity of aqueous and acetone extracts of five different fruits such as Kiwi, Persimmon, Pomegranate, Dragon and Noni were investigated. Recently peptic ulcer has become a common global problem because of change in life style. Among various mechanisms involved in the formation of gastric ulcers, free radicals generated during stress are one of the major causative factors for the gastric lesion through oxidative damage. Thus the best approach to control gastric ulcer would be to inhibit oxidative damage and acid secretion induced by the enzyme proton potassium ATPase. The present study therefore was focused on evaluation of inhibition of proton potassium ATPase, one of the causative factor for development of gastric ulcers and screening antioxidant activity to inhibit oxidative damage mediated gastric ulcers by the Kiwi, Persimmon, Pomegranate, Dragon and Noni fruits extracts which contained phenolics and other plant secondary metabolites that serve as good antioxidants.

The percentage of yield, carbohydrate and phytochemicals, antioxidant activity and inhibition of proton potassium ATPase activity of Kiwi, Persimmon, Pomegranate, Dragon and Noni fruits is depicted in table 1. The total yield of crude extracts from Kiwi, Persimmon, Pomegranate, Dragon and Noni fruits by using the solvents acetone and aqueous were $8.62 \%, 1.52 \%, 1.34 \%, 2.52 \%, 9.88 \%, 13.52 \%, 2.88 \%, 2.78 \%, 1.76 \%$ and $7.14 \%$ respectively, with reference to the fresh plant material. The yield was found to be maximum in fruit pomegranate aqueous extract, pomegranate acetone extract and least was in the fruit persimmon acetone extract.

Total phenolics was estimated for all the fruits like Kiwi, Persimmon, Pomegranate, Dragon and Noni at $100 \mu \mathrm{g}$ concentration as shown in Figure 1. Out of the ten fruit extracts, aqueous Kiwi fruit extract with $210 \mathrm{mg}$ gallic acid equivalent / $g$ of sample showed maximum amount of phenolics followed by the aqueous extract of Noni fruit with 96 $\mathrm{mg} / \mathrm{g}$ of sample and least amount of phenolics $16 \mathrm{mg} / \mathrm{g}$ of sample was observed in acetone extract of persimmon fruit. The phenols contain hydroxyls that are responsible for the radical scavenging effect mainly due to redox properties. These results gives a reason for the activity of these plants as antioxidant and how these plants extracts enable to scavenge the free radicals. Despite their wide distribution, the health effects of dietary polyphenols have come to the attention of nutritionists only in recent years. Researchers and food manufacturers have become more interested in polyphenols due to their potent antioxidant properties, their abundance in the diet, and their credible effects in the prevention of various oxidative stress associated diseases. 
Nanda / GSC Biological and Pharmaceutical Sciences 2019, 07(03), 107-115

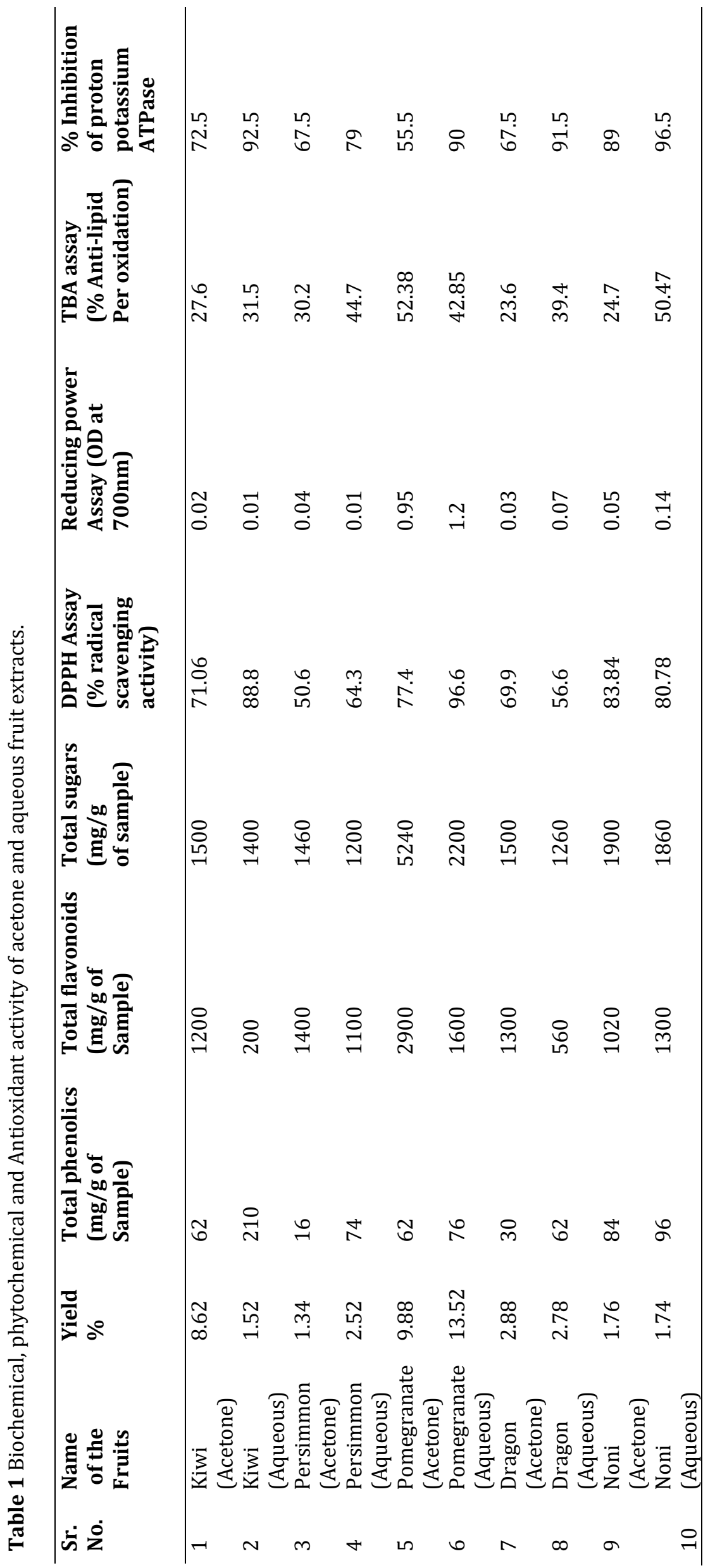




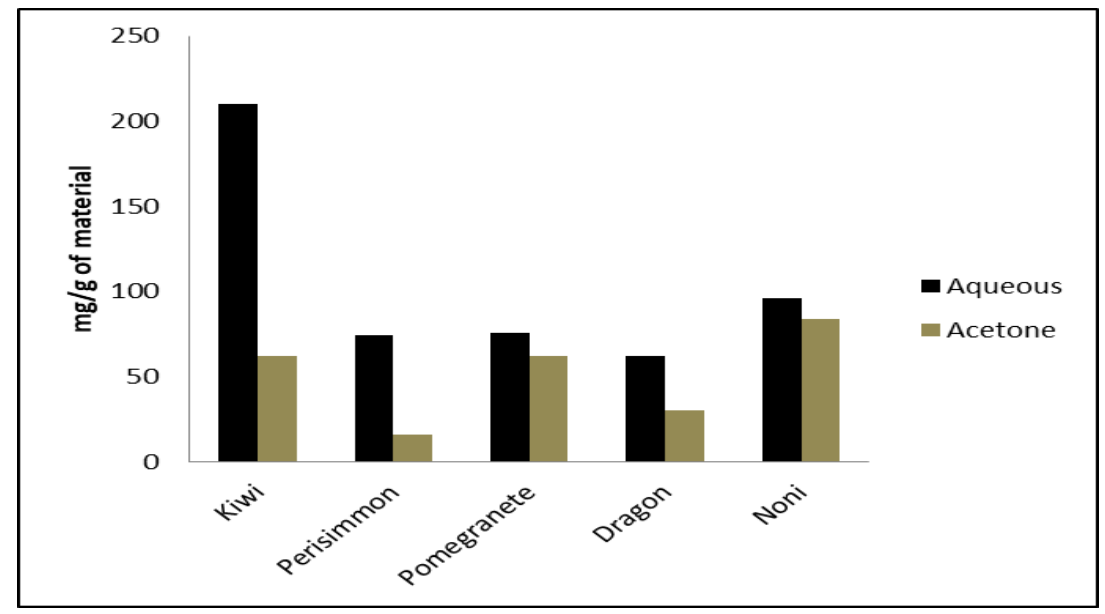

Figure1 Total phenolics in fruit extracts

Flavonoids are important secondary plant metabolites, which increase with plant stress. The total flavonoid content of fruits of acetone and aqueous extracts of Kiwi, Persimmon, Pomegranate, Dragon and Noni at $100 \mu \mathrm{g}$ concentration is found to be $1200,200,1400,1100,2900,1600,1300,560,1020,1300 \mathrm{mg} / \mathrm{g}$ of sample respectively as depicted in figure 2 . Acetone extract of pomegranate fruit was found to contain high amount of flavonoids and least being in aqueous extract of Kiwi fruit. The total flavonoid content of all the ten different fruit extracts was determined by the Aluminum chloride colorimetric method. These results gives a reason for the activity of these extracts as antioxidants and how these extracts enable to scavenge the free radicals. Flavonoids are hydroxylated phenolic substances known to be synthesized by plants in response to microbial infection and they have been found to be antimicrobial substances against wide array of microorganisms in vitro. Their activity is probably due to their ability to complex with extracellular and soluble proteins and to complex with bacterial cell wall. They also are effective antioxidant and show strong anticancer activities.

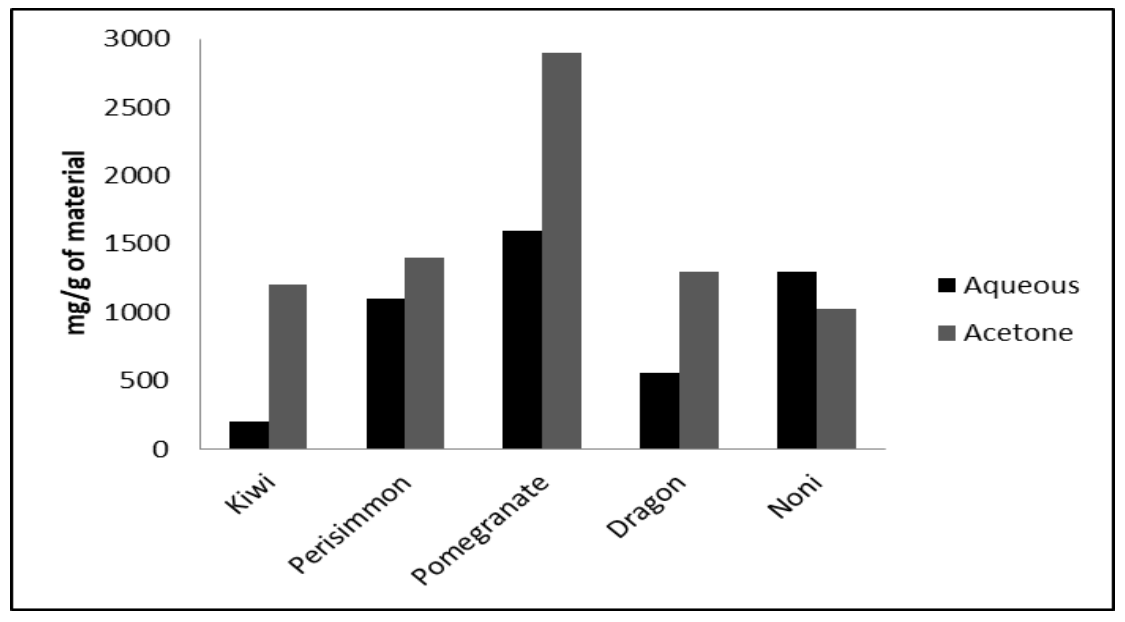

Figure 2 Total flavonoids in fruit extracts

The acetone and aqueous extracts of five different fruits Kiwi, Persimmon, Pomegranate, Dragon and Noni were screened for the total reducing sugars at $100 \mu \mathrm{g}$ concentration of extracts. These serve as the primary metabolites important for their sustainable development and that also indicates the nutritional aspects of different cereals. The results are depicted in the figures 3 and table 1 . The acetone extract of pomegranate fruit ranked the highest in total sugars with $5240 \mathrm{mg} / \mathrm{g}$ of sample and least was found in aqueous extract of persimmon fruit with $1200 \mathrm{mg} / \mathrm{g}$ of sample. 


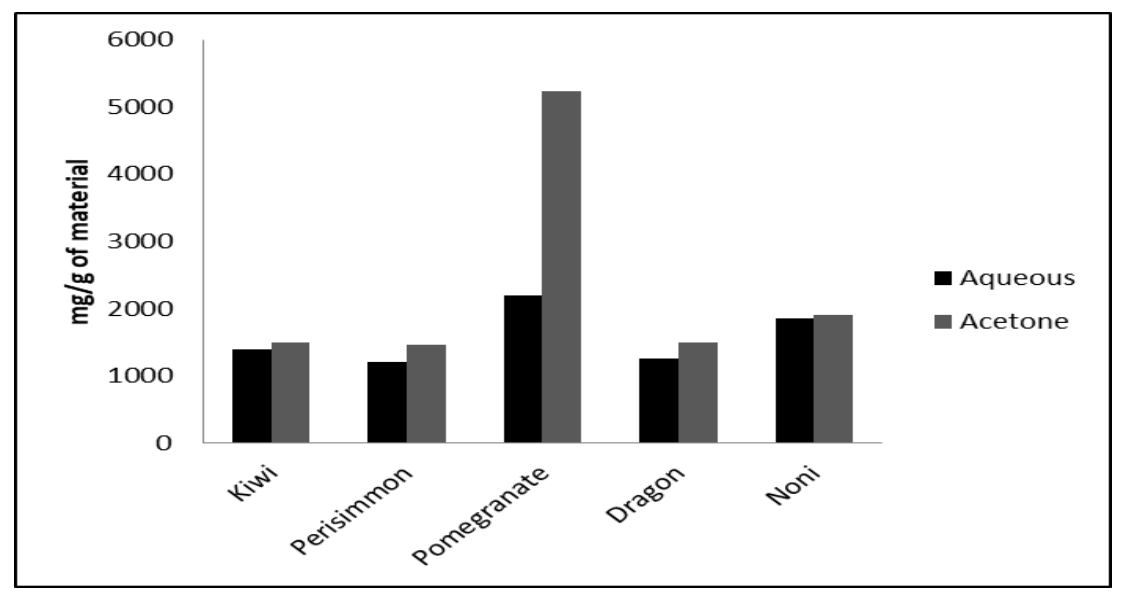

Figure 3 Total sugars in fruit extracts

Free radical scavenging potentials of all the fruits Kiwi, Persimmon, Pomegranate, Dragon and Noni at $100 \mu \mathrm{g}$ concentrations of acetone and aqueous extract was tested by the DPPH method and the results are shown in figure 4 . The aqueous pomegranate fruit extract showed maximum free radical scavenging activity of $96.6 \%$ followed by aqueous extract of Kiwi fruit with $88.8 \%$. Although phenolics, flavonoids and sugars are found to be less in aqueous extract of pomegranate fruit compared to other fruits it is having high antioxidant activity may be due to other phytochemicals such as terpenes, alkaloids, anthocyanins, saponins, cardiac glycosides, coumarins, tannins etc. Antioxidant activity is not determined by phenolics alone. Other non-phenolic compounds could have more potent antioxidant activities. Sometimes when compounds are present in a rich fraction form, synergism may enhance their bioactivity beyond what any one of the compound would produce. DPPH is a stable radical that has been used to evaluate the antioxidant activity of extracts. Antioxidant reacts with DPPH, which is a stable free radical, and converts it to $\alpha, \alpha$-diphenyl- $\beta$-picryl hydrazine. The degree of discoloration indicates the scavenging potentials of the antioxidant extract. The activity of extracts is attributed to their hydrogen donating ability.

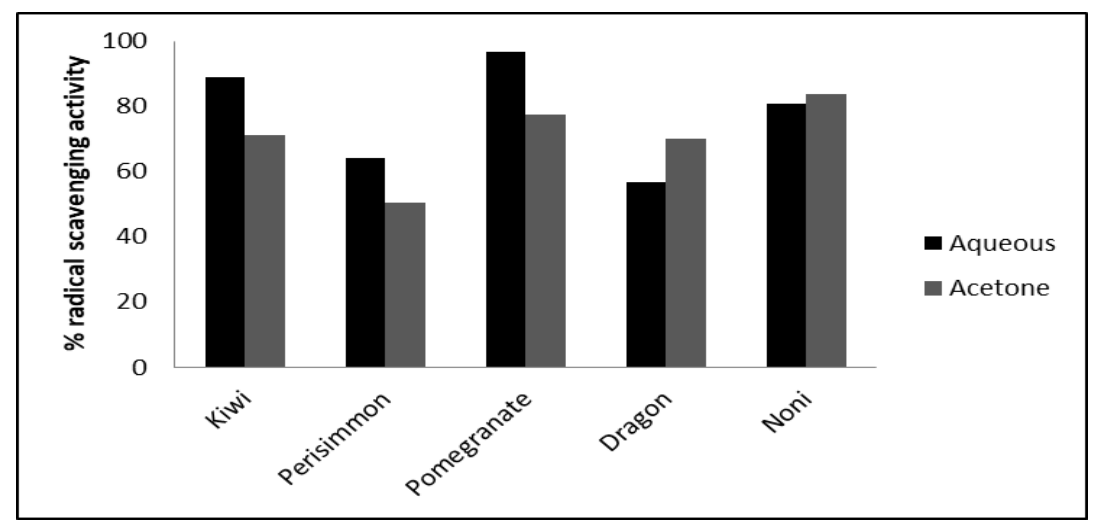

Figure 4 Percentage of radical scavenging activity in fruit extracts

The reducing capacity of a compound may serve as a significant indicator of its potential antioxidant activity. Figure 5 shows the reducing power activity of different fruit extracts at $100 \mu \mathrm{g}$ concentration using the potassium ferricyanide reduction method. At $100 \mu \mathrm{g}$ concentration of acetone and aqueous extract, the reducing power activity of fruits Kiwi, Persimmon, Pomegranate, Dragon and Noni showed absorbances of 0.02, 0.01, 0.04, 0.01, 0.95, 1.2, 0.03, 0.07, 0.05 and 0.14 respectively at $700 \mathrm{~nm}$. Thus, the good reducing activity was observed in aqueous pomegranate fruit extract correlating very much with DPPH antioxidant activity. Thus non-phenolic compounds may serve as reductones. This is followed by acetone extract of pomegranate fruit with 0.95 absorbance correlating with high amount of flavonoids and reducing sugars respectively. The reducing power activity is due to the presence of reductones (Phenolics) which have been shown to exert antioxidant action by breaking the free radical chain by donating a hydrogen atom. Reductones are also reported to react with certain precursors of peroxide, thus preventing peroxide formation. 


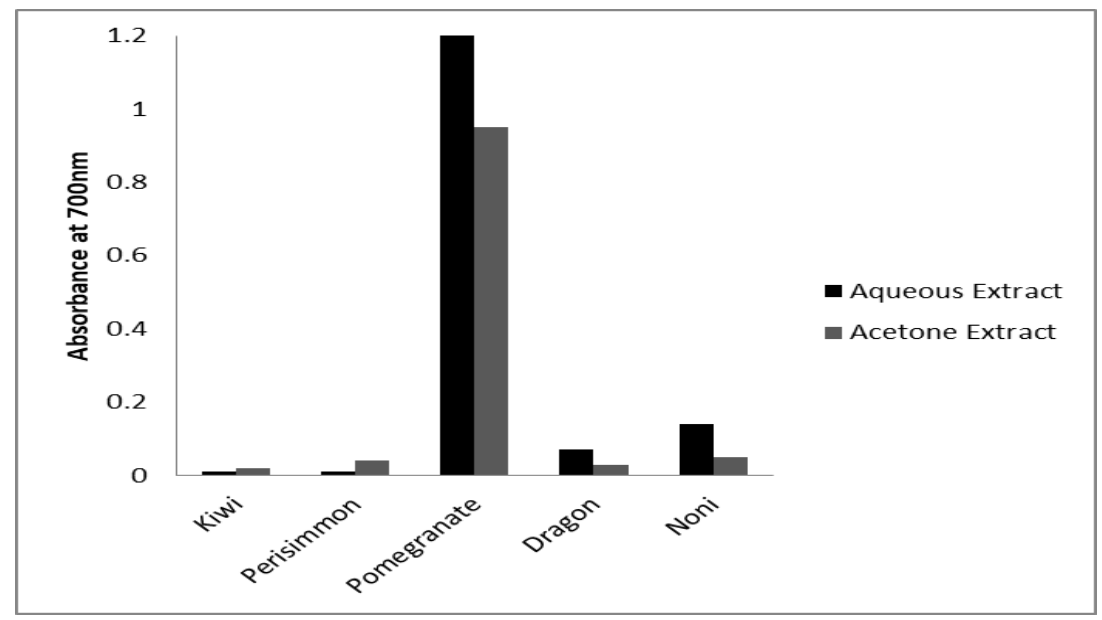

Figure 5 Reducing power activity in fruit extracts

Lipids and proteins are more susceptible to oxidative damage. The mechanism of free radical mediated damage during ulcer involves lipid peroxidation, which destroys cell membranes with the release of intracellular components, such as lysosomal enzymes, leading to further tissue damage. The lipid peroxidation might be a mechanism involved in the pathogenesis of gastritis associated or not to $\mathrm{H}$. pylori infection. The results of the effect of various edible flower extracts at $100 \mu \mathrm{g}$ concentration to prevent lipid peroxidation are shown in figure 6. At $100 \mu \mathrm{g}$ concentration, the fruits of acetone and aqueous extracts of Kiwi, Persimmon, Pomegranate, Dragon and Noni showed 27.6\%, 31.5\%, $30.2 \%, 44.7 \%, 52.38 \%, 42.85 \%, 23.6 \%, 39.4 \%, 24.76 \%$ and $50.47 \%$ of inhibition of lipid peroxide generation by this method. The inhibition of lipid peroxidation was found to be maximum in aqueous extract of pomegranate fruit with $52.38 \%$ followed by aqueous extract of Noni fruit with $50.47 \%$. Aqueous extract of pomegranate has high amount of flavonoids and reducing sugars.

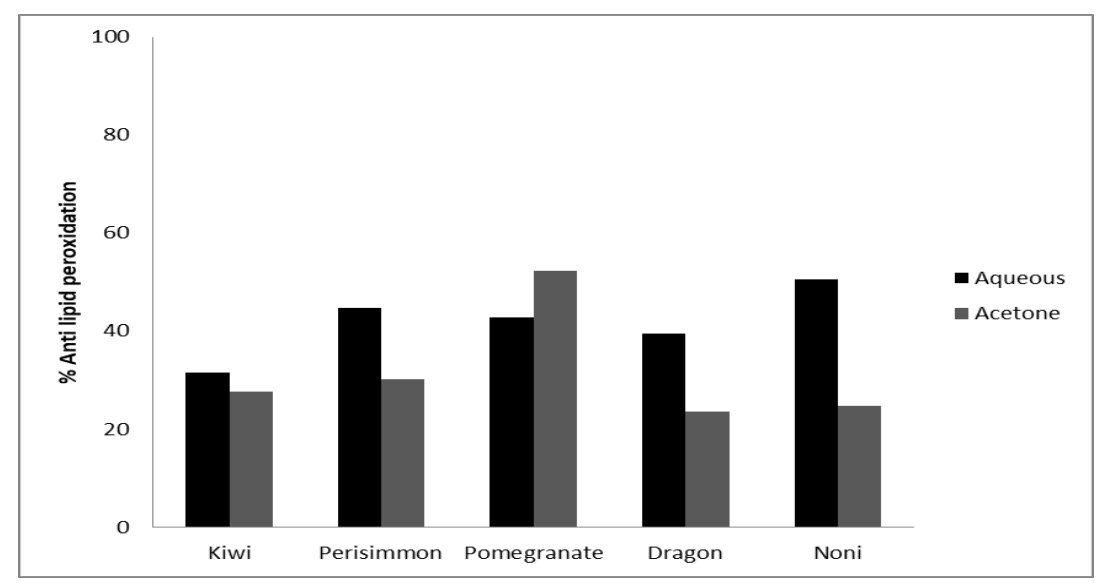

Figure 6 Percentage of anti- lipid peroxidation activity in fruit extracts

PPIs act selectively on the final stage of the process of gastric acid secretion, namely the $\mathrm{H}+\mathrm{K}+-\mathrm{ATPase}$ or proton pump. This enzyme represents an essential step in the process of secretion of $\mathrm{H}^{+}$. Therefore proton potassium ATPase inhibitory activity was screened for the fruits Kiwi, Persimmon, Pomegranate, Dragon and Noni respectively. The aqueous Noni fruit extract showed significant proton pump inhibitory activity of $96.5 \%$ in the goat gastric mucosal homogenate. This was followed by aqueous Kiwi fruit extract, aqueous Dragon fruit extract, aqueous Pomegranate fruit extract, Acetone Noni fruit extract with inhibition of $92.5 \%, 91.5 \%, 90 \%$ and $89 \%$ respectively. This study was carried out to evaluate the proton potassium ATPase inhibitory activity of different fruits and a possible mechanism to protect against gastric ulcer. Inactivation of the enzyme can be the major gastroprotective mechanism. 


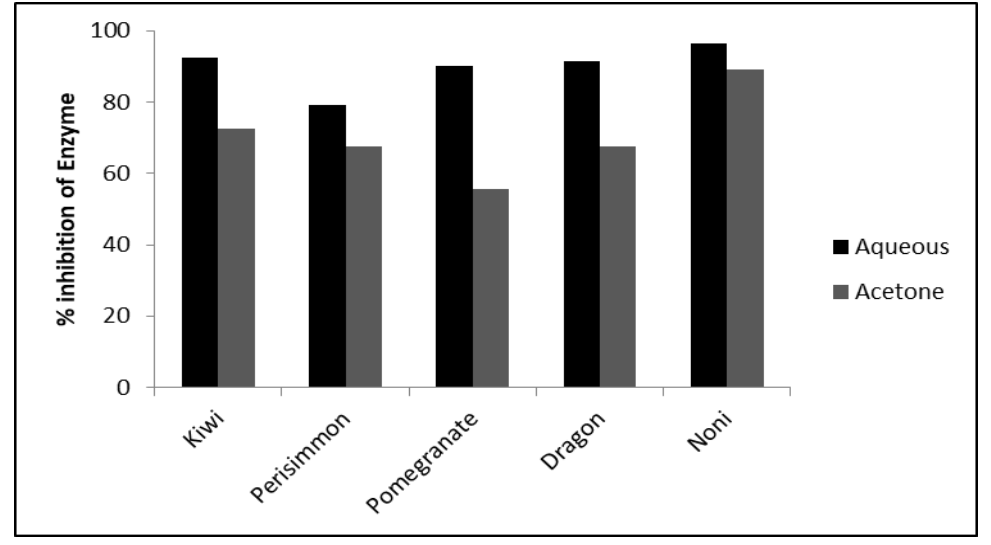

Figure 7 Percentage inhibition of Proton potassium ATPase in fruit extracts

\section{Conclusion}

Therefore the yield, reducing power activity and DPPH radical scavenging activity is found to be more in aqueous Pomegranate fruit. This may be due to presence of some other compounds other than Phenolics and flavonoids contributing to antioxidant activity. They may not be good inhibitors but inhibition is found to be there to certain extent. Phenolics were found be more in aqueous Kiwi fruit extract. They may be of less antioxidant ones. Flavonoids, sugars and inhibition of lipid peroxidation was found to be more in Acetone extract of Pomegranate fruit. Here flavonoids or glycosides may be contributing to anti-lipid peroxidation. The percentage of proton potassium ATPase inhibitory activity was found to be maximum in aqueous Noni fruit extract.

\section{Compliance with ethical standards}

\section{Acknowledgments}

The presenting author is grateful to Vision group on science and technology, Department of information technology, Biotechnology and Science \& technology, Karnataka Government, Bangalore-01, for financial support under the project CISEE, GRD-225 in carrying out this work.

\section{Disclosure of conflict of interest}

The author declares that they have no conflict of interest.

\section{References}

[1] Miller TA. (1987). Mechanisms of stress-related mucosal damage. American journal of Medicine. 83, 8-14.

[2] Ernst PB and Gold BD. (2000). The disease spectrum of Helicobacter pylori: The immunopathogenesis of gastroduodenal ulcer and gastric cancer. Annual Review of Microbiology, 54, 615-40.

[3] Langman MJ, Brooks P, Hawkey CJ, Silverstein F and Yeomans N. (1991). Non-steroid anti-inflammatory drug associated ulcer: Epidemiology, causation and treatment. Journal of Gastroenterology Hepatology, 6, 442-9.

[4] Demir S, Yilmaz M, Koseo lu M, Akalin N, Aslan D and Aydin A. (2003). Role of free radicals in peptic ulcer and gastritis. Turkish Journal of Gastroenterology, 14, 39-43.

[5] Phull PS, Green CJ and Jacyna MR. (1995). A radical view of the stomach: the role of oxygen-derived free radicals and anti-oxidants in gastroduodenal disease. European Journal of Gastroenterology \& Hepatology, 7 , 265-274.

[6] Süleyman Demir, Mustafa Yilmaz, Mehmet Koseo lu, Nalan Akalin, Diler Aslan and Ahmet aydin. (2003). Role of free radicals in peptic ulcer and gastritis. Turkish Journal of Gastroenterology, 14 (1), 39-43.

[7] Ordonez AAL, Gomez JD, Vattuone MA and Isla MI. (2006). Antioxidant activities of Sechium edule (Jacq). Food Chemistry, 97, 452-458. 
[8] Kaur C and Kapoor HC. (2002). Anti-oxidant activity and total phenolic content of some Asian vegetables. International Journal of Food Science and Technology, 37, 153-161.

[9] Zhishen J, Mengcheng T and Jianming W. (1999). The determination of flavonoid contents in mulberry and their scavenging effect on superoxide radicals. Food Chemistry, 64, 555-9.

[10] Blios, M.S. (1958). Antioxidant determinations by the use of a stable free radical. Nature, 181, 1199.

[11] Oyaizu M. (1986). Studies on products of browning reaction: antioxidative activity of products of browning reaction prepared from glucosamine. The Japanese Journal of Nutrition and dietetics, 44, 307-315.

[12] Halliwell B and Gutteridge, JMC. (1989). Free radicals in Biology and Medicine, $2^{\text {nd }}$ edn. Clarendon Press, Oxford.

[13] Sachs G, Spenney JG and Lewin M. (1978). H+ transport: Regulation and mechanism in gastric mucosa and membrane vesicles. Physiological Reviews, 58, 106-73.

[14] Fiske CH and Subbarow Y. (1925). The colorimetric determination of phosphorus. The Journal of Biological Chemistry, 66, 375-400.

[15] Waldum HL, Gustafsson B, Fossmark R and Qvigstad G. (2005). Antiulcer drugs and gastric cancer. Digestive Diseases and Sciences, 50(Suppl 1), S39-44.

[16] Goel RK and Sairam K. (2002). Anti-ulcer drugs from indigenous sources with emphasis on Musa sapientum, tamrahbasma, Asparagus racemosus and Zingiber officinale. Indian Journal of Pharmacology, 34, 100-10.

\section{How to cite this article}

Nanda BL. (2019). Antioxidant and proton potassium ATPase inhibitory activity in fruits. GSC Biological and Pharmaceutical Sciences, 7(3), 107-115. 